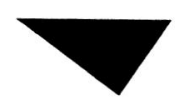

\title{
Três linhas de hibridação entre corpo e tecnologia
}

\author{
Fernanda Bruno \\ Universidade Federal do Rio de Janeiro
}

\section{Apresentação}

Arte, corpo e tecnologia são os temas de reflexão das páginas seguintes. Contemporâneo é o período ou o cenário onde os temas estão dispostos. Hibridação é o modo de relação entre os temas. Stelarc, performer que faz do seu próprio corpo uma matéria penetrada, estendida, ramificada e reprojetada pela tecnologia, é o foco de análise no campo da arte.

Agora, a sentença: a questão que orienta este trabalho é a da forma como, na contemporaneidade, o processo de hibridação entre corpo e tecnologia encontra expressão e ressonância na arte. Tal questão não se dirige ao interior da produção artística, suas condições de possibilidade e suas transformações. Não se trata de avaliar as alterações no conceito de obra, espectador e autor derivadas da arte tecnológica; tampouco pretende-se interrogar o quanto a arte e a produção científico-tecnológica podem se misturar sem corromperem-se mutuamente.

A arte que tematiza a hibridação entre corpo e tecnologia é utilizada aqui como um espaço de visibilidade deste processo da cultura contemporânea. Espaço de expressão, na medida em que o corpo e a tecnologia aí encontram não a sua pura materialidade reproduzida, mas as possibilidades de execução, de experiência e de sensibilidade extraídas de sua materialidade. Espaço de ressonância, pois as questões que emergem do processo de hibridação entre corpo e tecnologia - questões que seriam próprias à fillosofia, à tecnociência ou às ciências humanas - aí reaparecem e ao mesmo tempo assumem formas novas. 
"A importância do ciber pode muito bem residir no ato de o corpo trocar sua pele" . Este enunciado ilustra a forma como a hibridação entre corpo e tecnologia é realizada no trabalho de Stelarc: reprojetar e redimensionar o corpo, abalar seus limites e fronteiras pela mistura com a técnica. Três linhas de hibridação podem ser traçadas: a primeira constitui um movimento de ingestão da tecnologia, a segunda efetua acoplamentos homem-máquina que amplificam os ritmos do corpo e, por fim, a interface homem-rede ramifica o corpo possibilitando afecções entre agentes e espaços remotos.

\section{Linha 1 - Ingestões e Incorporações}

Em Escultura no estômago Stelarc trabalha com as idéias de "corpo oco' e de 'espaço hospedeiro': "a intenção foi projetar uma escultura para um estômago dilatado ... A tecnologia invade o corpo e funciona dentro dele não como um substituto protético, mas como um ornamento estético"2 (fig. I)

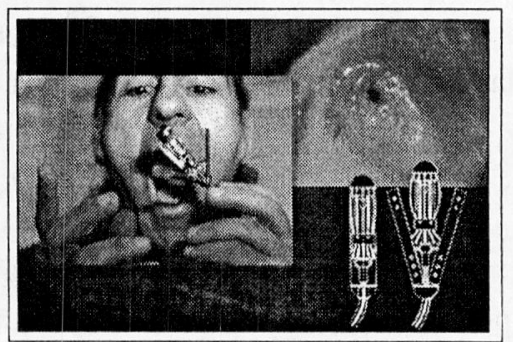

I - Stomach Sculpture

“A escultura está comprimida dentro de uma cápsula de $50 \mathrm{~mm}$ x $14 \mathrm{~mm}$ e amarrada à sua caixa de controle; ela é engolida e introduzida no estômago. O estômago é inflado com ar, usando-se um endoscópio. Um painel de circuitos lógicos e um servomotor abrem a escultura e a estendem, usando um cabo flexível e extensível, até a dimensão de $80 \mathrm{~mm} \times 50 \mathrm{~mm}$. Uma campainha piezoelétrica toca em sincronia com uma lâmpada que pisca dentro do estômago. A escultura é uma estrutura de extensão/retração, que emite sons e é auto-iluminada. (Ela é fabricada usando-se metais para implante, como titânio, aço inoxidável, prata e ouro). A escultura retrai-se para dentro de sua cápsula a ser removida"’3.

O corpo oco é o corpo sem limites ontológicos definidos. Corpo que pode abrigar técnica e arte, ou técnica como arte. Espaço hospedeiro de elementos estranhos à nossa condição estritamente orgânica. 
O agente externo não paralisa ou inviabiliza o corpo hospedeiro nem recompõe sua ordenação, ele aciona novos regimes de funcionamento. Stelarc não adere à tecnologia que se limita a fins protéticos reparatórios. Não se trata de utilizar a tecnologia para restituir nossas funções humanas debilitadas - e assim voltarmos a ser o que éramos , mas de possibilitar novas experiências e criar outras funções. Engolir uma escultura, fazer do estômago um ambiente estético, usar o endoscópio não como um instrumento de incisão médica mas de produção artística. "Como um corpo, não se observa mais a arte, não se age mais como arte, mas se contém arte. O corpo oco torna-se um hospedeiro, não para um eu ou uma alma, mas simplesmente para uma escultura".

O espaço interno é reconfigurado tanto no âmbito da relação órgão-função quanto no da relação corpo-técnica: os órgãos assumem outras funções ao mesmo tempo que a técnica deixa de habitar a extremidade ou a exterioridade do corpo. Escultura no estômago é, neste último sentido, o esfacelamento da pele como fronteira do mundo. Stelarc 'reencena' aqui o movimento contemporâneo de 'incorporação' da tecnologia.

Desde o marcapasso cardíaco, às placas de titânio e ao silicone, os artefatos técnicos ingressam no corpo humano recompondo seu ritmo, sua estrutura ou remodelando sua forma. A técnica deixa de ser apenas um instrumento que projeta e auxilia as funções do corpo no espaço externo e torna-se um elemento que pode ser ingerido e acomodado no interior do corpo.

Os limites entre o interno e o externo, entre o natural e o artificial e entre o mesmo e o outro são fluidificados nestas práticas cotidianas de 'incorporação' da tecnologia. Segundo os padrões do nosso corpo orgânico e biológico, o contato com a exterioridade se dá na extremidade do corpo - pele e órgãos do sentido; só aí há membrana, confusão do dentro e do fora. Quando o estímulo atravessa a extremidade, ingressa num espaço interno apartado do exterior até retornar como resposta ou ação no mundo. Agora o mundo toca diretamente os órgãos internos, as artérias e os ossos. Não apenas toca como regula, conserta e mesmo substitui.

A membrana se multiplica. O espaço topológico vital proposto por Simondon parece ganhar uma estranha visibilidade. Recusando a topografia que supõe um interior e um exterior absolutos, o autor propõe, no domínio da individuação do organismo vivo, uma topologia de diversos níveis de interioridade e de exterioridade: "o espaço das 
cavidades digestivas é uma exterioridade em relação ao sangue que irriga as paredes intestinais; mas o sangue é por sua vez um meio de exterioridade em relação às glândulas de secreção interna que derramam os produtos de sua atividade no sangue"s. No vivo, o dentro e o fora não são propriedades espaciais estáticas, são um processo dinâmico de "mediação transdutiva de interioridades e exterioridades" Esta topologia supõe uma cronologia do vivo que não coincide com a forma física do tempo. O espaço interior é correlativo a um tempo sucessivo condensado, a um passado que está presente "sem distância e sem atraso" na medida em que o que foi produzido pela individuação no passado faz parte do conteúdo do espaço interior que, por sua vez, está em contato topológico com o conteúdo do espaço exterior sobre os limites do vivo. A exterioridade é, assim, um futuro: dizer que uma substância pertence ao meio exterior significa dizer que ela pode advir. O presente é, por fim, "esta metaestabilidade da relação entre interior e exterior, entre passado e futuro" ${ }^{\text {, }}$ relação que caracteriza o processo de individuação.

Nas novas práticas de intrusão tecnológica, o exterior e o interior não significam apenas "estar fora" ou "estar dentro". O conhecido problema dos implantes e transplantes é fazer com que o organismo não rejeite este exterior que "está dentro". O "meio externo" propõe elementos que até então não participaram da constituição da matéria viva. Não apenas ingerimos elementos orgânicos e químicos - com os quais temos um parentesco material -, ingerimos componentes estranhos à nossa constituição natural. Os limites do corpo orgânico são reconfigurados nesta relação com um meio tecnológico que se acrescenta ao biológico, fisiológico e etológico.

Neste cenário de ingestões tecnológicas, a nanotecnologia ${ }^{9}$ apresenta-se como a promessa maior. A partir da manipulação de átomos e moléculas, pretende-se recombinar esta microestrutura da matéria para compor robôs microscópicos de extrema velocidade no processamento de informação. Um dos objetivos é tornar esses artefatos miniaturizados capazes de ingressar no corpo humano para, por exemplo, auxiliar o sistema imunológico ou reparar artérias danificadas. Outra possibilidade, que não é explicitada nos projetos oficiais e nos pedidos de auxílio financeiro, é construir implantes de memória e 'estimulantes' das demais faculdades mentais. Esses tecnoimplantes ou próteses interiorizáveis desvinculam ou 'liberam' o corpo de seus limites territoriais, orgânicos ou biológicos. Se as neurociências já permitem a ingestão de elementos químicos que mo- 
dulam nosso comportamento e nossa sensibilidade, as nanotecnologias prometem a ingestão de estimulantes técnicos - pastiIhas inteligentes - que não visam apenas suprir um déficit ou corrigir um desvio, mas superestimular e superexcitar as faculdades mentais que não mais estarão limitadas ao corpo orgânico e químico ${ }^{10}$.

Stelarc vê neste projeto, que situa-se entre a realidade e a ficção, a possibilidade de reconfigurar o corpo e nossa condição humana. "Miniaturizada e biocompativel, a tecnologia pousa sobre o corpo ... ela não é apenas presa ao corpo mas é também implantada ... como um componente, ela tem o potencial de dividir as espécies. Não é mais vantagem permanecer "humano" ou evoluir como espécie. A evolução termina quando a tecnologia invade o corpo. Talvez a tecnologia seja importante porque culmina numa consciência alternativa - que é pós-histórica, trans-humana e extraterrestre"l.

Considerar o corpo obsoleto é, para o performer-autor, a condição para desvincular a nossa forma atual de um tempo histórico acumulado que nos determina como espécie pertinente a um território. Por vezes essa 'saída do corpo' soa como uma nova versão de um velho hábito ocidental - sair da carne, sair da animalidade, sair da natureza ... Contudo, é possível ouvir aí mais do que uma simples repetição. Stelarc parece menos propor uma recusa do corpo do que a sua transformação - entrar em relação com novas modalidades de matéria e de ritmos é acionar um corpo por vir. Se por uma lado quer sair tanto do corpo biofisiológico quanto do corpo psicológico, atravessado pelo desejo ou por repressões, aposta que a saída está no próprio corpo quando ele se mistura com a técnica reprojetando seja a sua estrutura interna, seja as suas potencialidades de extensão e conexão. Passemos à segunda linha de hibridação.

\section{Linha 2 - Acoplamentos e ampliações}

Em uma performance que combina movimentos involuntários, voluntários e programados, Stelarc utiliza técnicas médicas, uma mão artificial e sistemas sonoros e visuais. O movimento do corpo "natural' é improvisado; a mão artificial, acoplada ao braço direito "como uma adição e não tanto como uma substituição protética"12, é movimentada por sinais de EMG dos músculos de seu abdômem e de suas pernas, podendo assim efetuar movimentos independentes; o braço esquerdo 'natural' é agitado à distância, independentemente de sua vontade, por estimuladores musculares. Os sons do motor do mecanismo da Terceira Mão e os sinais dos estimuladores são utilizados 
como fontes sonoras. A iluminação é composta como uma "manifestação dos ritmos do corpo"'s (fig. II).

O que está em jogo é a amplificação do corpo através da tecnologia. "É uma interação do controle fisiológico com a modulação eletrônica. Das funções humanas com a ampliação da máquina"'/4. Tanto a máquina quanto o corpo não se limitam às suas funções habituais. A máquina, tradicionalmente concebida como expressão da engenhosidade do espírito humano, como modelo de visibilidade do corpo, como substituição das forças naturais e da força de trabalho ou como prótese, torna-se um dispositivo de potencialização e de transformação do corpo. Acoplado à máquina, o corpo tem sua organização natural reconfigurada. Ao comportar um novo membro, novos eixos de comunicação e contato são estabelecidos: abdômem-mão, perna-mão. E o membro natural, o braço esquerdo, deixa de responder aos sinais cerebrais passando ao comando dos sinais elétricos da máquina. A relação entre o involuntário e o voluntário excedem o eixo central cérebro-corpo.

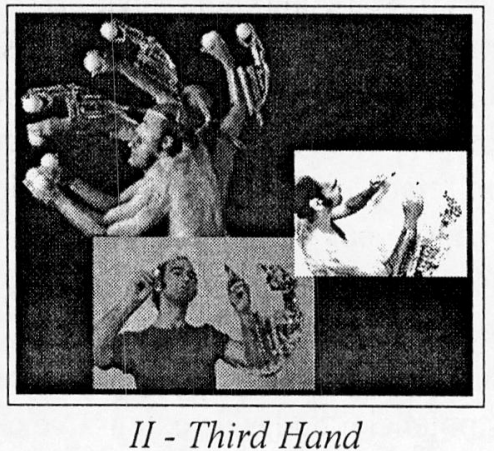

"Os processos do corpo amplificado incluem ondas do cérebro (ECG), músculos (EMG), pulsação (PLETHYSMOGRAM) e fluxo sangüíneo (DOPPLER FLOW METER). Outros transdutores e sensores monitoram o movimento dos membros e indicam a postura do corpo. O campo sonoro é configurado por zumbidos, trinados, cliques, baques, bipes - de sinais disparados, randômicos, repetitivos e rítmicos. A mão artificial ... é capaz de executar movimentos independentes, sendo ativada por sinais de EMG dos músculos abdominais e da perna. Ela tem um mecanismo para abrir e fechar a mão; o pulso pode girar $290^{\circ}$ nos dois sentidos e um sistema de feedback tátil para um 'sentido do tato' rudimentar. Enquanto o corpo ativa seu manipulador suplementar (a Terceira Mão), o braço esquerdo real é 
controlado a distância - posto em ação por dois estimuladores musculares. Eletrodos colocados nos músculos flexores e bíceps fazem com que os dedos se curvem, os pulsos se dobrem e o braço suba. O acionar do movimento do braço regula o ritmo da performance, e os sinais do estimulador são utilizados como fontes sonoras, assim como o som do motor do mecanismo da Terceira Mão. O corpo se move numa instalação luminosa estruturada e interativa que pisca e brilha, respondendo e reagindo às descargas elétricas do corpo - às vezes sincronizadas, às vezes se contrapondo. A luz não é tratada como uma iluminação externa do corpo, mas como uma manifestação dos ritmos do corpo"15.

O ritmo silencioso dos sinais musculares do abdômem e das pernas são amplificados, tornados audíveis e visíveis no movimento da terceira mão, um ritmo elétrico externo é imposto ao braço esquerdo natural - o movimento programado da máquina aciona gestos involuntários que, por sua vez, regulam o ritmo da performance. As descargas elétricas do corpo ganham visibilidade na luz que "pisca e brilha' ora em sintonia, ora contra os ritmos corporais. O interno e o externo, o visível e o invisível são mais uma vez embaralhados e alternados no acoplamento corpo-máquina.

A máquina anima o corpo e reconfigura o humano. Esta nova imagem da relação homem-máquina não é estranha à cultura contemporânea. Os artefatos tecnológicos não mais se reduzem a objetos inertes, instrumentos animados de acordo com a nossa vontade. Apresentamse, em grande parte, como 'lugares' de experiência de si e do outro e como ocasião de hibridação. Questões acerca das relações e fronteiras entre humano e não-humano, corpo e mente, natureza e artifício, presença e ausência, real e simulacro, espaço e tempo são recolocadas cotidianamente. Não é por acaso que tanto se fala da urgência de se pensar a ética no ciberespaço, nas tecnologias biomédicas e nas produções da biotecnologia. Sabemos que a revolução industrial também suscitou uma denúncia de riscos: alienação, dominação, mais-valia relativa. As máquinas ditas pós-industriais não representam tanto o espectro da dominação. Na relação homem-máquina, o que está em jogo não é tanto a consciência, a liberdade e a realização do homem na história, mas uma contínua interrogação acerca do humano - do que ele pode, do que o singulariza, do que ele se torna. O termo póshumano tem proliferado nos discursos contemporâneos sobre os efeitos e as possibilidades da produção tecnológica: ele aparece seja como grito de liberdade, seja como foco de denúncia. Uma espécie de nego- 
ciação de fronteiras parece ocorrer quando as máquinas tornam-se dispositivos de transformação do humano. O híbrido e o tão falado cyborg representam esta nova identidade negociada entre o humano e o não-humano.

\section{Linha 3 - Ramificações e Deslocamentos}

"Talvez o que signifique ser humano seja não reter nossa humanidade ..." ${ }^{\prime 6}$. Assim termina o artigo virtual de Stelarc acerca de sua mais recente performance on-line intitulada ParaSite: event for a invaded and involuntary body (fig. III). Contra um corpo sustentado por uma identidade e limitado por uma fisiologia e por um território, Stelarc quer pensar o corpo segundo sua 'conectividade'. A interface com a rede possibilita a ramificação do corpo - ele pode acessar e ser acessado por corpos distantes. Trocar a pele é, neste caso, ampliar as possibilidades de interface para além do contato local e real entre os corpos. A idéia de corpo hospedeiro retorna - agora ele abriga "agentes remotos"17. A Internet, por sua vez, deixa de ser meramente um meio de transmissão de informação, passando a ser também um veículo de transdução e de afetação física dos corpos. "O espaço eletrônico torna-se um meio de ação mais do que de informação"18. Stelarc procura criar uma espécie de antídoto contra os discursos que vêem nos espaços virtuais eletrônicos o desaparecimento do corpo e a dissolução do self. A ampliação da interface homem-rede potencializaria, ao contrário, estratégias individuais e coletivas de ramificação, projeção e afeção de corpos e consciências.

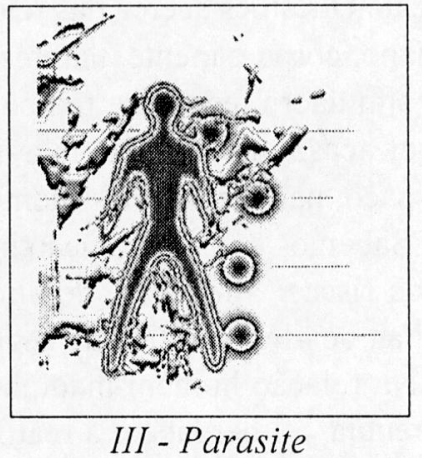

"Nas performances ParaSite o corpo tornado cyborg forma uma relação simbiótica/parasitária com a informação. Imagens provenientes da Internet são mapeadas sobre o corpo que, dirigido por um sistema de estimulação muscular, torna-se um nó ativo num sistema ner- 
voso virtual estendido. Além da ampliação cyborg da Terceira Mão, dos estimuladores musculares e dos elementos audiovisuais computadorizados, este sistema estende os parâmetros óticos e operacionais do corpo. Um sistema de busca personalizado reúne, analisa e cartografa as imagens JPEG recebidas. Em tempo real, os dados digitais são simultaneamente expostos sobre o corpo e seu meio ambiente imediato e, proporcionalmente às características dos dados, o movimento muscular é ativado involuntariamente. O movimento resultante é espelhado num espaço VRML no site da performance e, ao mesmo tempo, é recarregado num outro website como uma fonte potencial (e recursiva) de imagens para a ativação do corpo. Um dos resultados desta relação é o feedback entre o corpo e a Rede que é visualizado tanto no corpo real quanto no corpo virtual (VRML). A imagem acima é parte da visualização VRML da performance ParaSite" $"$.

Um dos sistemas que integram o conjunto de performances PuraSite é o Stimbod (Corpo estimulado), um software composto de um tela sensível ao toque em interface com um estimulador muscular múltiplo que permite a programação de movimentos involuntários do corpo, seja no próprio local ou em lugares remotos, através do toque nos muscle-sites do modelo do computador (fig. IV). "Corpos conectados e acoplados eletronicamente podem 'extrusar' a ação, sem que a consciência do corpo esteja 'nem totalmente aqui' nem 'totalmente lá" ${ }^{20}$.

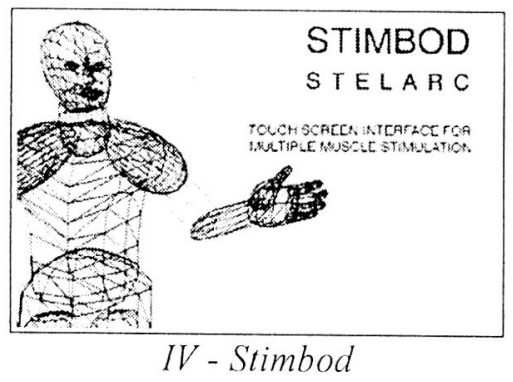

"Uma interface de tela sensível ao toque permite programar os movimentos do corpo apertando os locais onde estão os músculos no modelo do computador e/ou retomando e colando a partir de uma biblioteca de gestos. A carne alaranjada mapeia os possíveis locais, enquanto a carne vermelha indica os músculos que entram em ação. A simulação do movimento pode ser examinada antes da transmissão e da movimentação. Em um nível de simulação inferior, é um sistema 
instigador (prompting) do corpo, em um nível superior de estimulação, torna-se um sistema de acionamento do corpo"21.

Corpo e imagem confundem-se neste sistema interativo - o toque na imagem ativa o corpo - próprio ou do outro. E mesmo que se ative o próprio corpo, o movimento produzido não resulta de nenhuma contração interna dos músculos - mais uma vez, mistura de ritmos voluntários e involuntários. Quando se aciona ou se é acionado por um outro corpo - é a imagem que permite a afecção entre os corpos. Na imagem, os corpos se tocam. "As imagens não são mais ilusórias quando elas se tornam interativas .... os fantasmas projetam e potencializam o corpo" 22 .

Em ParaSite encontra-se presente um tema comum nas análises sobre a hibridação entre corpo e tecnologia - o problema do corpo próprio. As tecnologias do virtual permitem experimentar sem corpopresente, prescindir do espaço-tempo natural para perceber e sentir paisagens, objetos, corpos. Essas possibilidades diluem a oposição entre o corpo-objeto, passível de ser conhecido do exterior por analo-

84 gia ao corpo do outro, e o corpo-sujeito, experimentado do interior e indisponível à exploração objetiva, pois não está jamais diante do sujeito mas é o próprio sujeito como condição de toda exploração do mundo, corpo que não se possui, mas corpo que se é - corpo próprio $^{23}$. O corpo-objeto acoplado e interfaceado com a tecnologia, pode perceber, sentir e tocar prescindindo em parte do corpo-sujeito que encontra-se, pois, parcialmente destituído do lugar de condição de toda a experiência. A experiência do corpo próprio, que testemunhava a ancoragem no mundo e constituía a condição de acesso aos objetos exteriores, perde seu privilégio de ser sempre presente e condição de toda presença. O corpo-objeto, por sua vez, também acha-se modificado na medida em que suas propriedades materiais não apenas se oferecem ao olhar desencarnado do cientista que apreenderia suas características gerais e estáveis. O corpo-objeto, o corpo orgânico-material, torna-se 'ocasião' de experiência e espaço de transformação, o que permite Stelarc apontar a necessidade de inserção do artista nesses novos processos de diferenciação do corpo. Diversificar o corpo em forma e função é potencializar as possibilidades de ser um corpo pela transformação dos meios de se ter um corpo - "como supostos agentes livres, as capacidades de 'ser um corpo' são restringidas por 'ter um corpo"'24. 
'Como supor, a partir de então, que as coisas continuam na normalidade'?, pergunta Virilio, aterrorizado com as declarações de Stelarc, embora veja aí apenas um "delírio sintomático" de uma "vítima que consente" 25 . Vítima da precipitação das tecnociências sobre o corpo. Fagocitose do espaço interior, colonização dos órgãos e vísceras do corpo animal do homem, esfacelamento do espaço do corpo e da temporalidade particular do corpo vivo - eis algumas da imagens usadas por Virílio para compor o diagnóstico de nossa mais recente doença. O autor vê na expansão da mistura com a técnica a retração do humano. Investir na hibridação é descartar nossos últimos atributos humanos, aliás curiosamente próximos do animal.

Esta reação de Virilio tem um aspecto curioso: o corpo é a dimensão reivindicada como o resquício do humano. Na tentativa de apreender a especificidade desta reivindicação do corpo, cabe lembrarmonos do modo como o corpo, em nosso passado recente, foi chamado à cena num movimento de crítica da cultura. Freud e Nietzsche servem de exemplo. O primeiro via na recusa do corpo, na "supressão das pulsões', o fator preponderante no incremento das neuroses: "a influência prejudicial da civilização reduz-se principalmente à repressão nociva da vida sexual dos povos (ou classes) civilizados através da moral civilizada que os rege" ${ }^{26}$. A forte reação de Freud à teoria da degenerescência é uma das marcas de sua posição quanto ao sentido do corpo na constituição do sujeito. Nietzsche, por sua vez, acusa os desprezadores do corpo - a metafísica, a moral e a religião - de criarem a ilusão de que estaria na razão, na consciência e na alma a causa do bem e da liberdade. Contra esta ilusão, o corpo: "eu sou todo corpo e nada além disso; e alma é somente uma palavra para alguma coisa no corpo ... há mais razão em teu corpo que na tua melhor sabedoria" 27 .

Apesar das conhecidas diferenças entre os dois autores, percebe-se um ponto comum na forma como o corpo era requerido: tratava-se de 'rachar' o demasiadamente humano que, no quadro moderno, era cultural, moral, social ou institucional. No cenário contemporâneo ${ }^{28}$, diferentemente, o corpo é requerido como a garantia de nosso mínimo de homem, como o que nos distingue do artifício e assegura a unidade da experiência e dos limites orgânicos e territoriais, quando estes arriscam ser simultaneamente invadidos e ampliados pela tecnologia.

Tratar-se-ia então de uma reação ao corpo mecanizado e maquinizado da tecnociência? Ainda que sim, é necessário avaliar a sua singularidade. Como vimos acima, a reação fenomenológica ${ }^{29}$ ao 
corpo descrito pela medicina e pela física não encontra aqui uma continuidade calma. $\mathrm{O}$ estatuto da produção e da intervenção científica e tecnológica rompeu em parte com a herança cartesiana que se apresentava na ciência analisada por Merleau-Ponty. A máquina como modelo do corpo é, no pensamento cartesiano, uma forma de absorção do invisível pelo visível. Através da máquina, "o corpo interior é então exposto aos olhos" ${ }^{30}$. O modelo da máquina permite separar o corpo da experiência que temos dele. Substituindo um corpo vivido do interior por um corpo visto do exterior, o modelo da máquina assegura o conhecimento verdadeiro do corpo pois 'regula' a participação da imaginação e dos sentidos no entendimento ${ }^{31}$. E o corpo-máquina determina negativamente o que a alma não é: movimento cego e involuntário, regido pelas leis mecanicistas e pelo automatismo. Todo o conhecimento provém, pois, da alma, de um pensamento desencarnado que conhece à medida em que se desvencilha do corpo e da experiência sensível para refletir sobre si mesmo.

Contra tais suposições, Merleau-Ponty deseja pensar a experiência primeira do mundo que supõe um sujeito encarnado e anterior a todo exercício de reflexão. A absorção do invisível pelo visível, derivada da redução metódica do desconhecido ao conhecido, parece sofrer uma espécie de inversão. O pensamento é primordialmente relação com o invisível, com o desconhecido; o visível só se dá a partir desta relação com o invisível. Deste modo, o pensamento deve deixar de se limitar ao puro conhecimento e, num mesmo movimento, a filosofia deve diferenciar-se da ciência, pois deve conduzir-se ao que possibilita todo o visível. Do corpo "sem interior e sem $s i$ " 32 da ciência, distingue-se o "meu corpo (que) é ao mesmo tempo vidente e visível ... É um si, não por transparência, como o pensamento ... mas um si por confusão" 33 .

Quando a máquina deixa de ser o modelo de um corpo regido pelo automatismo e torna-se um dispositivo de ramificação e transformação do corpo, o mecanicismo cartesiano perde, num mesmo movimento, seu lugar de modelo da produção científica e tecnológica. Além disso, as máquinas não só simulam o mecanismo do corpo, mas funções mentais - o que é uma heresia para a máquina de Descartes. Os artefatos técnicos, hibridados com o corpo, não apenas emprestam sua visibilidade ao último, eles reconfiguram seu ritmo, sua estrutura interna, suas possibilidades de experiência, sua relação com o espaço e o tempo. Esta nova modalidade de corpo-objeto não deixa intocada, como vimos, a oposição entre corpo-sujeito e corpo-objeto. Ter um 
corpo, até há bem pouco tempo, era uma fatalidade. E, nesta medida, a experiência de ser um corpo apresentava-se como aquilo que excede ao simples fenômeno biofisiológico e se dirige ao sentido, experiência sempre inacabada, jamais totalmente constituída, pois é relação com o Ser, "abertura ao mundo". Doravante, a experiência de ter um corpo ganha uma certa plasticidade e isto pode, sem dúvida, não representar nenhuma transformação positiva ou mesmo indicar a continuidade de um determinismo tecnológico, mas também pode haver aí uma ocasião para recolocarmos a questão acerca das possibilidades do corpo. Questão que não se endereça ao inventário das proezas tecnológicas ou das 'descobertas' científicas, mas que incide sobre os limites com os quais vínhamos demarcando as condições de nossa experiência e de nossa 'humanidade'.

No trabalho de Stelarc, a mistura com novas matérias, agentes e espaços expressa menos um movimento de controle do corpo e do pensamento do que um desejo de ramificação e hibridação - desejo de "não reter a nossa humanidade". Ser humano é aí uma espécie de exercício de transmutação que faz apelo à alteração do modo como temos lidado com o corpo-objeto, escavando aí - neste domínio que parecia ser exclusivo da tecnociência - um espaço para a arte. E o artista "emprega o seu corpo" ${ }^{34}$... de outra maneira. "O corpo não como um sujeito, mas como um objeto - não um objeto de desejo, mas um objeto de projeto" ${ }^{35}$.

\section{Bibliografia}

ANDRIEU, Bernard (1993). Le Corps Dispersé: une histoire du corps au XXe siècle. Paris: Harmattan.

BAUDRILLARD, Jean (1993). A Ilusão do Fim ou a greve dos acontecimentos. Lisboa: Terramar.

DOMINGUES, Diana (org.) (1997). A Arte no século XXI: a humanização das tecnologias. São Paulo: Unesp.

FREUD, Sigmund (1976). "Moral Sexual Civilizada e Doença Nervos Moderna" in Obras Completas - vol. IX. Rio de Janeiro: Imago.

GUENANCIA, Pierre (1991). Descartes. Rio de Janeiro: Jorge Zahar.

LÉVY, Pierre (1994). L'Intelligence Collective. Paris: La Découverte.

MERLEAU-PONTY, Maurice (1945). Phénoménologie de la Perception. Paris: Gallimard. 
(1984). "O Olho e o Espírito" in Os Pensadores - Merleau-Ponty. São Paulo: Abril Cultural.

NIETZSCHE, Friedrich (1983). Assim Falou Zaratutra. Rio de Janeiro: Civilização Brasileira.

SIMONDON, Gilbert (1964). L'Individu et sa Genèse PshycoBiologique. Paris: PUF.

STELARC (1997). Home Page: http://merlin.com.au/stelarc/ index.html

VIRILIO, Paul (1996). A Arte do Motor. São Paulo: Estação Liberdade.

\section{Notas}

1 Stelarc (1997). "Das estratégias psicológicas às ciberestratégias: a protética, a robótica e a existência remota" in Domingues, D. (org.). A Arte no século XXI: a humanização das tecnologias. São

88 Paulo: Unesp, p. 52.

2 Idem, p. 57.

3 Ibidem.

4 Ibidem.

5 Simondon, G. (1964). L'Individu et sa Genèse PhysicoBiologique. Paris: PUF, p. 261.

6 Idem.

7 Ibidem, p. 263.

8 Ibidem, p. 264.

9 A nanotecnologia é uma técnica que age em escala molecular e visa compor, manipulando átomo por átomo, matérias 'inteligentes' miniaturizadas (um nanômetro corresponde à bilionésima parte do metro) capazes de armazenar uma grande quantidade de informação e de processar em alta velocidade. Cf. Lévy, P. (1994). L'Intelligence Collective. Paris: La Découverte, pp. 50-62.

10 Cf. Virilio, P. (1996). A Arte do Motor. São Paulo: Estação Liberdade, pp. 91-114.

11 Stelarc. (1997), op. cit., p. 55.

12 Idem, p. 56. 
13 Ibidem.

14 Ibidem.

15 Ibidem.

16 Stelarc (1997). http://www.merlin.com.au/stelarc/index.html

17 Ibidem.

18 Stelarc (1997), op.cit., p. 60.

19 Idem.

20 Idem, p. 59.

21 Ibidem, pp. 58-9.

22 Ibidem, p. 61.

23 Cf. Merleau-Ponty, M. (1945). Phénoménologie de la Perception. Paris: Gallimard.

24 Stelarc (1997), op. cit., p. 54.

25 Virilio, P. (1996), op. cit., p. 101.

26 Freud, S. (1976). "Moral sexual civilizada e doença nervosa moderna" in Obras Completas - vol. IX. Rio de Janeiro: Imago, p. 191.

27 Nietzsche, F. (1983). Assim falou Zaratustra. Rio de Janeiro: Civilização Brasileira, p. 51.

28 Além de Paul Virilio, outros autores partilham desta visão. Cf. Baudrillard, J. (1993). A Ilusão do fim ou a greve dos acontecimentos. Lisboa: Terramar; Andrieu, B. Le Corps Dispersé: une histoire du corps au XXe siècle. Paris: Harmattan.

29 Limitamo-nos aqui à visão de Merleau-Ponty.

30 Beaune, J.C. (1980). L'automate et ses mobiles. Paris: Flammarion apud Guenancia, P. (1991). Descartes. Rio de Janeiro: Jorge Zahar, p. 50.

31 Cf. Guenancia, P. (1991), op. cit.

32 Merleau-Ponty, M. (1984). "O Olho e o Espírito" in Os Pensadores - Merleau Ponty. São Paulo: Abril Cultural, p. 89.

33 Idem, p. 88.

34 Merleau-Ponty (1984), op. cit., p. 88.

35 Stelarc (1997), op. cit., p. 55. 
